\title{
The gap between practice and genetics education of health professionals: HuGEM survey results
}

E. Virginia Lapham, $P h D^{1}$, Chahira Kozma, MD ${ }^{1}$, Joan O. Weiss, $M S W^{2}$, Judith L. Benkendorf, MS, CGC ${ }^{3 *}$, and Mary Ann Wilson, $B A^{2}$

\begin{abstract}
Purpose: To determine the genetics education needs and priorities of dietitians, occupational therapists, physical therapists, psychologists, speech-language-hearing specialists, and social workers. Methods: A random sample mail survey of 3600 members of 6 national health professional organizations was undertaken in 1998 and resulted in 1958 responses. Results: A majority worked with clients with genetic conditions, most were providing genetic services to some clients, few had high confidence in providing genetic services, most had little or no education in genetics, and two-thirds wanted continuing education. Conclusion: The study shows a critical need for genetics education of allied and counseling health professionals. Key Words: genetics education, survey of health profes-
\end{abstract} sionals. Genetics in Medicine, 2000:2(4):226-231.

Key Words: genetics education, survey of health professionals

During the past decade, the field of medical genetics has witnessed significant advances in mapping and sequencing the human genome. This has provided an increased understanding of common conditions such as diabetes, most cancers, diseases of the heart, mental illnesses, and some personality traits. ${ }^{1}$ These advances, fueled largely by the Human Genome Project (Time, July 3, 2000), have brought genetic issues to the forefront of health care and created an increased need for genetic services. ${ }^{2}$

At the same time, there are $<3300$ genetics professionals in the United States certified by the American Board of Medical Genetics and the American Board of Genetic Counseling (Sharon Robinson, American Board of Medical Genetics, personal communication, 1999). These genetics professionals are unable to meet even the current demand for genetic services, and in the near future, it is anticipated that they will provide services almost exclusively to the most complex referrals. ${ }^{3}$ As a result, primary health care practitioners from a variety of professions in addition to medicine and nursing will increasingly be faced with clients who have need for genetics information and skills. Nongenetic health professionals are often the first to see clients who present with speech, hearing, motor, nutritional, or mental health concerns. Their clients may need interpretation of genetic risk, psychosocial counseling related to genetic diagnoses and referrals for genetic testing, genetic

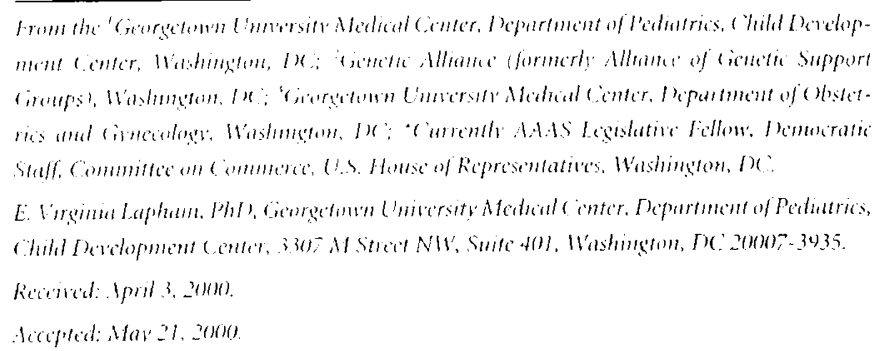

counseling, and other specialized genetic services. ${ }^{4-6}$ Health professionals will also need to assume responsibility for protecting their clients' confidentiality and privacy of genetic information. ${ }^{7,8}$

Since its inception in 1990, the Ethical, Legal and Social Implications (ELSI) Research Program of the National Human Genome Research Institute at the National Institutes of Health has recognized the important societal implications of genetic advances and the lack of preparedness of health professionals to apply the new advances in clinical settings. ${ }^{9}$ In 1994 , a multidisciplinary committee formed by the Institute of Medicine of the National Academy of Sciences examined issues of genetic testing and recommended that health professionals, including social workers and psychologists as well as nurses and physicians, be trained in the ethical, legal, and social issues surrounding genetic testing. ${ }^{10}$ However, recent surveys and observations indicate that physicians, ${ }^{11}$ nurses, ${ }^{12-14}$ and other health professionals ${ }^{15,16}$ are not adequately informed about the role of genetics in health care.

Despite this lack of training, a 1995 study of 329 health professionals in 52 of the 71 University Affiliated Programs (UAPs) around the country showed that a majority of UAP health professionals were already providing some kinds of genetic services to their clients. The health professionals included dietitians, educators, nurses, occupational therapists, physical therapists, physicians, communication specialists, psychologists, and social workers. A majority of these professionals were discussing with their clients the extent to which there is a genetic component to their developmental or medical problems, some were referring patients for genetic testing and genetic counseling, and at least a quarter were providing counseling about genetic concerns. This study was part of the first phase of the Human Genome Education Model (HuGEM) Project, a 
collaborative project of Georgetown University Medical Center and the Alliance of Genetic Support Groups.

To further investigate the findings of this exploratory study, a random-sample survey of members of six professional associations who included direct service providers was carried out in 1998 as part of the second phase of the Human Genome Education Model (HuGEM) Project. The collaborating health professional associations were American Dietetic Association (ADA), American Occupational Therapy Association (AOTA), American Physical Therapy Association (APTA), American Psychological Association (APA), American Speech-LanguageHearing Association (ASHA), and the National Association of Social Workers (NASW). (See Table l.) At the time of the survey, the memberships of the six organizations totaled 570,000 with 330,909 (ADA, 68,000; AOTA, 55,000; APA, 150,000; APTA, 60,000; ASHA, 85,000; and NASW, 152,000) members identified as direct service providers.

\section{METHODOLOGY}

The questionnaire used in the 1995 HuGEM exploratory study was revised for the 1998 survey and incorporated input from representatives of the collaborating organizations and the HuGEM II Advisory Committee. Consumers of genetic services identified by the Alliance of Genetic Support Groups reviewed the questionnaire at each stage for sensitivity to consumer issues. The questionnaire was then provided to the Survey Research Center (SRC), University of Maryland to identify potential problems with question wording or response measures and to carry out the survey. Each association drew a random sample from members who were direct service providers and sent the list of names and addresses directly to SRC.
For confidentiality reasons, the lists were available only to SRC staff who coded the responses.

A pretest of 25 members from each association (150 total) revealed no major problems with the quality of the sample or potential problems with response rates. Coded questionnaires were mailed to 3,600 health professionals (600 from each association) along with a cover letter asking for participation. A reminder postcard was sent out a week later. A month after start of the survey, a second copy of the questionnaire was sent to nonrespondents along with a modified cover letter stressing the importance of participating in the study. Additional postcard reminders were sent to all nonrespondents and responses were accepted until September 15, 1998. The overall response rate was $57 \%$ (this rate was considered by the Survey Research Center to be an acceptable rate for a mail survey) and ranged from $47 \%$ of the APA sample to $62 \%$ of ADA and $64 \%$ of ASHA samples.

\section{SURVEY FINDINGS}

The demographic characteristics of the respondents were found to be typical of the association memberships in gender, age range and work experience. The majority was female (range of 53\% to 98\%), mean age of mid forties (range of 22 to 88 years) with an average of 15 years of professional experience. Most respondents reported Caucasian as their ethnocultural identity with $<8$ percent self-identified as African American, Asian American, Hispanic, Native American, and unspecified. This response rate is slightly less than the rate of minority representation reported by the collaborating associations.

The highest completed education degrees of respondents varied by profession with more than $98 \%$ of psychologists

Table 1

Professional associations that participated in the study

American Dietetic Association (ADA) is a membership organization founded in 1917. At present, there are approximately 70,000 members that include clinical and community dietetics professionals, consultants, food service managers, educators, researchers, dietetic technicians, and students. Dietetics is the high-tech science of applying food and nutrition to health.www.eatright.org

American Occupational Therapy Association, Inc. (AOTA) is a membership organization founded in 1917. Currently, there are 60,000 members that include occupational therapists, occupational therapy assistants, and occupational therapy students. The profession is a vital health service whose practitioners help to restore and sustain the highest quality of productive life to persons recovering from illnesses or injuries, or coping with developmental disabilities or changes resulting from the aging process. www.aota.org

American Physical Therapy Association (APTA) is a membership organization founded in 1921. There are now more than 70,000 physical therapists, physical therapist assistants, and students of physical therapy. Briefly, physical therapists are health care professionals who evaluate and treat people with health problems resulting from injury or disease. They assess joint motion, muscle strength and endurance, function of heart and lungs, and performance of activities required in daily living. www.apta.org

American Psychological Association (APA) is a membership organization founded in 1892. The association consists of more than 159,000 researchers, educators, clinicians, consultants, and students. The discipline of psychology is described as the understanding of behavior that applies to every conceivable setting from scientific research centers to mental health care services. www.apa.org

American Speech-Language-Hearing Association (ASHA) is a membership organization founded in 1925. Currently, there are more than 97,000 speechlanguage pathologists, audiologists, and speech, language, and hearing scientists in the United States and internationally. The mission is to promote the interests of and provide the highest-quality services for professionals in audiology, speech-language pathology, and speech and hearing science and to advocate for people with communication disabilities. www.asha.org

The National Association of Social Workers (NASW) is a membership organization founded in 1955. At this time, there are nearly 155,000 members who are professional social workers. The primary mission of NASW is to enhance human well-being and help meet the basic human needs of all people, with particular attention to the needs and empowerment of people who are vulnerable, oppressed, and living in poverty. www.naswdc.org 
holding doctorates, $94 \%$ of social workers and speech-language pathologists holding master's degrees, and just over half of respondents from the other three professions holding bachelor's degrees. Almost $80 \%$ of respondents reported taking no formal courses in genetics in either graduate or undergraduate programs and a third did not recall having genetics content in any courses. While most respondents got genetic information from the media during the previous year, over $80 \%$ had heard little or nothing about the Human Genome Project. More than one in four had received genetic information from clients within the previous six months. About one-third had received genetics content from conferences and continuing education courses. Only $8 \%$ had received genetics content from genetic professionals.

\section{Work settings and client characteristics}

Respondents worked in hospitals, clinics, geriatric facilities, mental health agencies, private practice and other settings in which health services are provided to persons with genetic conditions. Nearly two-thirds of the respondents worked in metropolitan cities or suburbs while the others worked in small towns and rural areas. Most of the respondents worked in multidisciplinary settings, half of which included physicians and nurses. Only $5 \%$ of respondents indicated medical genetics/ genetic counseling to be among the disciplines in their primary work settings. Thirty percent of respondents worked primarily with clients who are 65 years or older and another thirty percent worked with children and youth 20 years and under. The respondents estimated that $16 \%$ of their clients had a genetic disorder, $31 \%$ had conditions that were both genetic and environmental, and the remaining $53 \%$ were considered to have conditions that were only environmental.

\section{Provision of genetic services}

Based on responses from the 1995 HuGEM Survey in which UAP respondents from many health professions were providing genetic services to their clients, respondents in this survey were asked about four specific genetic services (Table 2). A majority $(70 \%)$ of respondents from each of the six associations reported that they had discussed the genetic component of problems with at least a few of their clients. About $30 \%$ reported providing counseling about genetic concerns to at least a few of their clients. No attempt was made to learn what was included in the counseling. However, it was noted that the counseling was carried out by over half of the psychologists and social workers and about one in six of the occupational and physical therapists. In contrast, $<20 \%$ of respondents referred clients for genetic counseling and nearly as many $(15 \%)$ referred clients for genetic testing.

\section{Job responsibilities and confidence}

Respondents reported carrying out a variety of job responsibilities that could involve knowledge and use of genetic information (Table 3). These included taking family histories, writing reports, and referring clients to community resources. A list of genetic services that could be included in the job responsibilities was provided and respondents rated their confidence in carrying out each service. Confidence was measured on a five-point scale from 1 (low confidence) to 5 (high confidence). Since $<10 \%$ of respondents rated themselves a number 5 on any of the services listed, high confidence was defined as numbers 4 or 5 and low confidence defined as 1 or 2 .

A comparison of job responsibilities and genetic services that could be part of the jobs showed significant gaps as follows:

1. Intake interviews, family and/or medical histories. As part of their job responsibilities during the previous year, a majority of respondents from each profession had conducted intake interviews and taken family or medical histories. However, only $21 \%$ had high confidence in eliciting genetic information as part of these interviews and histories.

2. Assessments and interventions. Assessments were carried out by more than three-fourths of the respondents during the prior year according to the responsibilities of each profession and $86 \%$ provided some sort of disciplinary or therapeutic intervention. Yet, only $16 \%$ of respondents reported having high confidence in discussing the genetic basis of disorders/ conditions with their clients as part of their assessments and interventions.

3. Counseling services. Psychologists and social workers are the major providers of counseling services in this country ${ }^{17}$ and a majority of APA and NASW respondents ( $87 \%$ and $81 \%)$ had provided counseling services in the previous year. Yet, $<$ $30 \%$ reported high confidence in providing counseling to clients making decisions about whether or not to have genetic testing and about half were confident in providing psychosocial counseling related to coping with a newly diagnosed genetic disorder.

4. Communicating information. Most of the respondents $(86 \%)$ interpreted results of their disciplinary assessments to clients and families. Yet, few respondents (17\%) reported high

Table 2

Genetic services provided by respondents by professional association: percent who carried out service with at least a few of their clients

\begin{tabular}{lccccccc}
\hline With how many of your clients have you: & ALL & ADA & AOTA & APA & APTA & ASHA & NASW \\
\hline 1. Discussed the genetic component of problems & 69.7 & 67.7 & 52.4 & 88.2 & 68.2 & 70.5 & 77.6 \\
2. Made referrals for genetic counseling & 19.1 & 6.3 & 18.4 & 33.2 & 7.8 & 26.1 & 27.1 \\
3. Made referrals for genetic testing & 15.0 & 5.9 & 13.8 & 22.3 & 8.6 & 21.0 & 20.8 \\
4. Provided counseling about genetic concerns & 29.9 & 24.1 & 15.3 & 55.4 & 18.0 & 24.6 & 52.3 \\
\hline
\end{tabular}


Table 3

Professional responsibilities of respondents by professional association: percent who carried out role within past year

\begin{tabular}{|c|c|c|c|c|c|c|c|}
\hline In your primary job, which of the following have you done in the past year? & All & $\mathrm{ADA}$ & AOTA & APA & APTA & ASHA & NASW \\
\hline 1. Conduct intake interviews & 70.9 & 76.8 & 50.5 & 88.3 & 58.0 & 64.8 & 90.7 \\
\hline 2. Take family histories & 67.2 & 54.2 & 51.0 & 86.4 & 55.5 & 70.8 & 91.0 \\
\hline 3. Take medical histories & 65.1 & 55.1 & 60.5 & 59.5 & 91.4 & 67.6 & 56.3 \\
\hline 4. Provide disciplinary assessments & 76.9 & 82.2 & 86.4 & 65.8 & 77.1 & 76.9 & 68.1 \\
\hline 5. Provide disciplinary interventions/treatments/therapy/counseling & 85.7 & 90.2 & 91.6 & 78.7 & 80.8 & 83.5 & 86.8 \\
\hline 6. Interpret assessment results to clients/families & 87.6 & 88.7 & 93.4 & 84.0 & 87.9 & 97.4 & 70.0 \\
\hline 7. Write reports & 91.9 & 81.1 & 97.5 & 89.6 & 95.6 & 97.1 & 90.1 \\
\hline 8. Participate in case conferences & 84.5 & 81.0 & 91.1 & 80.5 & 72.1 & 92.4 & 87.5 \\
\hline 9. Provide case management & 52.8 & 28.7 & 40.1 & 52.5 & 48.2 & 73.9 & 72.9 \\
\hline 10. Refer clients to community-based resources & 83.7 & 74.9 & 81.3 & 89.1 & 80.5 & 83.4 & 95.5 \\
\hline 11. Supervise students & 62.9 & 68.4 & 64.3 & 68.4 & 69.4 & 58.1 & 48.9 \\
\hline 12. Present papers at professional meetings & 23.7 & 16.4 & 23.4 & 42.2 & 15.4 & 22.9 & 26.4 \\
\hline 13. Other & 7.3 & 6.1 & 8.0 & 8.4 & 6.2 & 6.0 & 9.3 \\
\hline
\end{tabular}

confidence in providing guidance to the clients with genetic disorders about what impact the genetic condition might have on future development. High confidence ranged from $10 \%$ of dietitians to $24 \%$ of psychologists. More than $90 \%$ of respondents wrote reports during the previous year. Yet, less than one in four respondents had high confidence in obtaining written informed consent before releasing genetic information in reports to third parties.

5. Making referrals. A majority of respondents (84\%) had referred clients to community based resources during the previous year. Yet, $<20 \%$ ( $9 \%$ of physical therapists to $29 \%$ of social workers) reported high confidence in referring clients for genetic counseling. Just over one-third of the respondents had high confidence in making referrals for psychosocial counseling related to genetic issues.

6. Preparing the next generation of professionals. Over $60 \%$ of the respondents supervised students and about one in four had presented papers at professional meetings during the previous year. Yet a minority of respondents had high confidence in any area of genetic services.

\section{Genetics education and confidence}

To consider the effects of genetics education on confidence in carrying out genetic services, respondents were divided into three discrete categories according to the amount of genetics education they had received. The categories were 1) respondents who had taken one or more course in genetics, 2 ) respondents with genetics content in course work, and 3 ) respondents with no genetics education. The more genetics education a respondent had, the more confident he/she was in providing 7 of the 9 genetic services listed (Table 4). Each of the seven services, including eliciting genetic information as part of family histories or making referrals for genetic counseling, was statistically significant at $\mathrm{p}<.05$. The two genetic services that were not significant for the whole group per- tained to counseling (see Table 4, Questions 6 and 7), but they were statistically significant for psychologists. There was a trend for social workers with more genetics education to be more confident in providing counseling services, but it was not statistically significant.

\section{Desire for continuing education in genetics}

Nearly two-thirds of the respondents said they would be interested in attending continuing education workshops in genetics at their professional conferences. More than one-third reported interest in having training to provide education on genetic issues to colleagues, patients, and/or students. To assess what issues or topics would be most useful to the health professionals in providing continuing education, thirteen possible topics were listed on the questionnaire and respondents rated each topic on a scale of 1 (very useful) to 4 (not useful). The mean ranking for the topics ranged from 1.75 to 2.5 , indicating that almost all of the topics were at least somewhat useful. The topics were ranked as follows with the means provided in parentheses.

- Role of genetics in common disorders such as stroke, heart disease, and cancers (1.75)

- Overview of human genetics (1.98)

- Identifying genetic resources for clients (2.09)

- Helping clients cope with a new genetic diagnosis (2.10)

- Genetic information and racial/ethnic concerns (2.12)

- New treatments for genetic disorders including gene therapy (2.17)

- Privacy and confidentiality issues in releasing genetic information to others such as health insurers, schools, and employers (2.25)

- Communicating genetic information to clients (2.25)

Five of the top 8 priorities were the same for each association although in somewhat different order. For example, commu- 
Table 4

Confidence of health professionals in roles incorporating knowledge and use of genetic information by formal education in genetics

\begin{tabular}{|c|c|c|c|c|c|c|}
\hline \multirow{2}{*}{$\begin{array}{l}\text { Role } \\
\text { Q: In working with individuals and families with genetic conditions, } \\
\text { please indicate how confident you are in your ability to carry out } \\
\text { each of the following? }\end{array}$} & \multicolumn{6}{|c|}{ Formal education in genetics* } \\
\hline & All & $\begin{array}{l}1 \text { or more } \\
\text { courses }\end{array}$ & $\begin{array}{l}\text { Some } \\
\text { genetics } \\
\text { content }\end{array}$ & None & $\mathrm{N}$ & $p$ Value \\
\hline Q-1. Elicit genetic information as part of family/medical history & 26.3 & 32.8 & 26.6 & 21.1 & 1448 & 0.0000 \\
\hline Q-2. Discuss the genetic basis of disorders/conditions with clients & 16.1 & 23.1 & 15.3 & 12.1 & 1442 & 0.0000 \\
\hline Q-3. Make referrals for genetic counseling & 19.7 & 27.0 & 20.0 & 14.2 & 1333 & 0.0000 \\
\hline $\begin{array}{l}\text { Q-4. Make referrals for psychosocial counseling related to genetic } \\
\text { issues }\end{array}$ & 35.7 & 40.7 & 35.8 & 31.9 & 1400 & 0.0102 \\
\hline $\begin{array}{l}\text { Q-5. Provide guidance to clients with genetic disorders about what } \\
\text { impact the genetic condition may have on future development }\end{array}$ & 16.0 & 19.6 & 16.6 & 12.8 & 1414 & 0.0029 \\
\hline $\begin{array}{l}\text { Q-6. Provide counseling to clients making decisions about whether } \\
\text { or not to have genetic testing }\end{array}$ & 11.8 & 13.3 & 12.6 & 9.8 & 1290 & 0.1688 \\
\hline $\begin{array}{l}\text { Q-7. Provide psychosocial counseling related to coping with a } \\
\text { newly diagnosed genetic disorder or test result }\end{array}$ & 20.2 & 22.4 & 19.4 & 19.8 & 1297 & 0.4022 \\
\hline $\begin{array}{l}\text { Q-8. Obtain written informed consent to release genetic } \\
\text { information to third parties }\end{array}$ & 24.3 & 30.1 & 26.4 & 17.0 & 1185 & 0.0001 \\
\hline Q-9. Provide training/education on human genetics to students & 3.8 & 8.3 & 3.8 & 0.8 & 1240 & 0.0000 \\
\hline
\end{tabular}

* Percentage of high confidence of all \%. Statistically significant: higher confidence $(4,5)$ vs. lower confidence $(1,2)$.

nicating genetic information to clients was priority 5 for ASHA members and 6,7 , or 8 for members of other associations. The priority topics identified by the respondents provided the basis for the curriculum content of the core courses for health professional educators, the workshops for practitioners, and the materials developed by the HuGEM Project.

\section{SUMMARY AND DISCUSSION}

This is a random sample study of direct service providers who are members of six health professional organizations. During the previous year, the professionals provided a variety of therapeutic and psychosocial counseling services in hospitals, clinics, and other medical and community settings serving clients with genetic concerns. The finding that a majority of the respondents had discussed genetic issues with at least some of their clients may indicate both the increased need for genetic services and the clients' expectations that these direct service providers can understand their genetic concerns and be able to provide accurate information. The candid responses in acknowledging a lack of confidence in providing genetic services combined with the majority wanting continuing education in genetics shows a strong recognition by the respondents of needing genetics education. It was surprising that more respondents provided counseling about genetic concerns than have referred for genetic counseling since most respondents were located in metropolitan areas where genetics professionals are more likely to be found. It was also unexpected to find almost as many respondents referring for genetic testing as referring for genetic counseling. This indicates a need for guidelines on making appropriate referrals.

The finding that few respondents reported high confidence in carrying out genetic services was consistent with the mini- mal or no genetics education in their professional training. A positive correlation between amount of genetics education and confidence in carrying out genetic services affirms the value of providing genetics education. Selected top priorities for education show the desire for knowledge about basic genetics as well as a desire for skills in how to apply the knowledge. Skill building could include learning how to use pedigrees in eliciting genetic information as part of family history taking, guidelines for getting written informed consent and incorporating genetic information in reports to third parties, and recommendations for when and how to make referrals to genetic professionals.

Limitations of the study include having insufficient information such as telephone numbers to follow up on nonrespondents to the survey to see whether there were differences between respondents and nonrespondents that could have biased the sample. For example, if professionals who gave genetic information to clients were more likely to respond than those who did not give genetic information to their clients, the rate would still be significant but less than the $70 \%$ reported. An apparent bias is the response rate from respondents of minority ethnocultural members of the associations being less than the rates provided by the associations. This raises caution about applying the findings to other than Caucasian members of the associations. It also suggests the need for other surveys to determine the education needs of health professionals who are ethnocultural minorities to ensure appropriate and sensitive content.

\section{Recommendation}

The overall recommendation from this study is for genetics professionals to be aware of the educational needs of all direct 
service providers in health settings and to consider the provision of continuing education in genetics as a high priority. Courses could be offered at medical centers, university settings, and at conferences of the associations. Additionally, a list of basic competencies in genetics for all health professionals has been approved by the National Coalition of Health Professional Education in Genetics that may be helpful in developing curricula. (NCHPEG is an organization started in 1996 by the National Institutes of Health, American Medical Association, and the American Nursing Association to promote genetics education for all health professionals.) Genetics professionals may also partner with the 60 educators and leaders from the six associations who received 30 hours of training in genetics from the HuGEM Project in May and July of 1999 and who are now scheduling continuing education courses across the country. An element of the HuGEM core courses that was most memorable and helpful to many of the health professionals and is highly recommended to other genetics educators was the inclusion of consumers on panels and in workshops sharing their experiences and recommendations.

It will take a coordinated effort among genetics professionals, professional associations, and this country's academic institutions to assure that primary and continuing education efforts lead to the enactment of genetic competencies and the fulfillment of the identified priority education topics by all health care professionals early in the $21^{\text {st }}$ century.

\section{Acknowledgments}

Appreciation for assistance with the survey is expressed to:

1) Representatives of the collaborating health professional organizations: Donald Beless (CSWE), Judith A. Gilbride (ADA), Andrew Guccione (APTA), Ann M. Johnson (CSWE), Penny Kyler (AOTA), Jo Linder-Crow (APA), Sharon E. Moss (ASHA), and Toby Weismiller (NASW).

2) Faculty of Georgetown University: Suzanne M. Bronheim, Kathryn L. Camp, Toby Long, Janet Thomas, and Sharon Willig.

3) All members of the HuGEM Advisory Committee.
Appreciation is also expressed to Wei Liu for research assistance.

The Human Genome Education Model Project is funded by the National Institutes of Health, National Human Genome Research Institute, Ethical, Legal and Social Implications Research Program.

\section{References}

1. Collins, FS. Shattuck Lecture-Medical and societal consequences of the human genome project. N Engl J Med 1999;341:28-36.

2. Collins FS. Preparing health professionals for the genetic revolution. JAMA 287 1997;1285-1286.

3. Institute of Medicine. Personnel issues in human genetics. In: Andrews LLB, Fullerton JE, Holtzman NA, Motulsky AG, editors. Assessing genetic risks: implications for health and social policy. Washington, DC: National Academy Press, 1994;202223.

4. Reynolds PI, Benkendorf JL. Genes and generalists: why we need professionals with added competencies. West J Med 1999;171:375-379.

5. Scanlon C, Fibison W. Managing genetic information: implications for nursing practice. Washington, DC: American Nurses Publishing, 1995; 1-50.

6. Hayflick SI, Eiff MP. Role of primary care providers in the delivery of genetics services. Community Genet 1998;1(1):18-22.

7. Gostin L. Health Care information and the protection of personal privacy: ethical and legal considerations (Part 2). Ann Intern Med 1997;127:46-53

8. Beauchamp TL, Childress JF. Professional-patient relationships: principles of biomedical ethics. Oxford: Oxford Press, 1994;395-461.

9. Thomson E. The ethical, legal and social implications program at the National Human Genome Research Institute, NIH. In: Smith E, Sapp W. Plain talk about the Human Genome Project: a Tuskegee University Conference on its promise and perils. . . and matters of race. Tuskegee, Alabama: Tuskegee University Press, 1997 123-130.

10. Institute of Medicine. Personnel issues in human genetics. In: Andrews LB, Fullerton JE, Holtzman NA, Motulsky AG. Assessing genetic risks: implications for health and social policy. Washington, DC: National Academy Press, 1994

11. Hofman KJ, Tambor ES, Chase GA, Geller, Faden, RR, Holtzman NA. Physicians knowledge of genetics and genetic tests. Acad Med 1993;68:625-631

12. Scanlon $C$, Fibison W. Managing genetic information. implications for nursing practice. Washington, DC: American Nurses Association, 1995.

13. Kenner $C$. National coalition for health professional education in genetics. $A A C N$ Clin Issues Crit Care Nurs 1998;9:582-587.

14. Anderson G. Genetics education in healthcare. Nurs Spectr (Wash D C) 1999;9:24

15. Laufer $\mathrm{RH}$, and Beardsall $\mathrm{AH}$. A survey of professionals: preliminary results: Insti tutes for Disability Studies: A University Affiliated Program. Hattiesburg, Mississippi: University of Southern Mississippi, 1995.

16. Kolb SE, Aguilar MC, Dinenberg M, Kaye Cl. Genetics education for primary care providers in community health settings. J Community Health 1995;24:45-59.

17. O'Neil IV. Profession dominates in mental health, NASW NEWS, Washington DC, 1999. 